\title{
Gorham's Disease With Chest Wall Involvement:A Case Report and a Review of the Literature
}

\author{
Abolghasem Daneshvar Kakhaki ${ }^{1}$; Kian Khodadad ${ }^{2}$; Saviz Pejhan ${ }^{1,}$; Shirin Karimi ${ }^{3}$; \\ Mehrdad Arab ${ }^{1}$; Reza Saghebi ${ }^{1}$; Mohammad Behgam Shadmehr ${ }^{1}$; Roya Farzanegan ${ }^{1}$ \\ ${ }_{1}^{1}$ Tracheal Diseases Research Center, National Research Institute of Tuberculosis and Lung Diseases (NRITLD), Shahid Beheshti University of Medical Sciences, Tehran, IR Iran \\ ${ }^{2}$ Chronic Diseases Research Center, National Research Institute of Tuberculosis and Lung Diseases (NRITLD), Shahid Beheshti University of Medical Sciences, Tehran, IR Iran \\ ${ }^{3}$ Mycobacteriology Research Center, National Research Institute of Tuberculosis and Lung Diseases (NRITLD), Shahid Beheshti University of Medical Sciences Tehran, IR Iran \\ *Corresponding Author: Saviz Pejhan, Tracheal Diseases Research Center, National Research Institute of Tuberculosis and Lung Diseases (NRITLD), Shahid Beheshti University of Medi- \\ cal Sciences, Tehran, IR Iran. Tel: +98-2127121000, Fax: +98-2126109484, E-mail: spejhan@yahoo.com
}

Received: May 16, 2013; Revised: January 26, 2014; Accepted: August 25, 2014

\begin{abstract}
Introduction: Gorham's disease is a rare disorder characterized by osteolysis and abnormal vascular growth within bones. Diagnosis of Gorham's disease is often delayed and for accurate and early diagnosis high clinical suspicion is crucial. No specific treatment is available. Management options include surgery, radiation therapy and medical therapy. We aimed to present the first case of Gorham's disease with chest wall involvement in Iran. By review of the literature we discussed important issues of this rare disease including clinical findings, diagnosis and treatment options.

Case Presentation: We present a 48-year-old man with a history of dyspnea following a blunt chest trauma who was admitted to our clinic several times due to reaccumulation of pleural fluid and chylothorax. Gorham's disease was finally established according to clinical manifestations and radiological findings including massive osteolysis in his left ribs and also histological examination.

Discussion: According to review of the literature and considering all treatment modalities the patients was successfully treated with a combination of radiotherapy, pamidronate and thalidomide. We suggest that this disease should be considered among differential diagnoses of patients with chest pain, pleural effusion and/or chylothorax with an unknown reason and more importantly history of chest trauma. In suspected cases, it is essential to examine biopsy specimens of the bone adjacent to the inflammated tissues in order to confirm diagnosis.
\end{abstract}

Keywords:Gorham Disease; Osteolysis; Chylothorax

\section{Introduction}

Gorham's disease (GD) is a rare condition of uncertain etiology characterized by progressive resorption of one or more skeletal bones (1). Non-malignant proliferation of vascular or lymphatic vessels within the bone leads to resorption and replacement of the involved bone with fibrovascular connective tissue $(2,3)$. Occurrence in the chest wall may lead to chylous pleural or pericardial effusion, which could be life threatening (2-4).

As far as we know, this is the first case of GD with chest wall involvement in Iran. Here we present this case and explain how he was successfully treated with combination of radiotherapy, pamidronate and thalidomide. The clinical manifestations, radiological and histological features and various methods of treatment are also discussed.

\section{Case Presentation}

We describe here a case of Gorham's disease, who was admitted to our center during August 2006. The patient was a non-smoker, 48-year-old man presenting dyspnea and pain in the left hemithorax following a chest blunt trauma three months before referral. Chest x-ray (CXR) showed left pleural effusion and a chest tube was inserted. The fluid was serosanguinous, exudative (Table 1) and negative for malignancy. All other lab tests were within normal limits. Thus the chest tube was removed and the patient was discharged. After a few days severe dyspnea and pain brought the patient back to the hospital. In the new CXR, reaccumulation of fluid was detected. Chest CT-scan revealed left-sided pleural effusion, left lung collapse and extra thoracic soft tissue edema.

With the probable diagnosis of incompletely removed hemothorax, the patient underwent thoracoscopy, which was converted to limited thoracotomy due to the considerable amount of fibrinous secretions and multiloculation. Decortication was performed and multiple biopsies were taken which did not show any specific diagnosis in microscopic examination. On the ninth postoperative day the lung was expanded and the patient was discharged with a final diagnosis of hemothorax secondary to trauma. Three months after discharge, the patient re-

Copyright ( ) 2014, Iranian Red Crescent Medical Journal. This is an open-access article distributed under the terms of the Creative Commons Attribution-NonCommercial 4.0 International License (http://creativecommons.org/licenses/by-nc/4.0/) which permits copy and redistribute the material just in noncommercial usages, provided the original work is properly cited. 
turned with the complaint of chest pain, softening and excavation in the anterior left hemithorax. Chest CT revealed mild pleural effusion in the left hemithorax along with nodular thickness of pleura, destruction of left anterior ribs and suspected masses. The CT guided biopsy of pleural masses was not diagnostic (Figure 1). According to the CT findings, anterolateral thoracotomy was performed. No mass or tumoral tissue was found except for pleural thickness, diffuse inflammation of soft tissues and complete destruction of anterior ribs. Although multiple biopsies were taken from inflammated tissues and pleura, non-specific diagnosis was obtained from histological examination. On the 13th day, the patient was discharged yet 12 days after discharge, the patient returned with swelling of the left hemithorax and left flank. A remarkable amount of fluid and collapse of left lower lobe and lingula were detected in the chest CT-scan. A chest tube was inserted and daily secretions through the chest tube were remarkable (between 800 and $1500 \mathrm{cc}$ ). The fluid seemed to be chylous and was confirmed as chylous by lab tests (Table 2). Ultimately due to indefinite diagnosis, repeated open biopsy was decided. Complete thoracoto- my was performed and intraoperative findings included complete destruction of anterior ribs (second to sixth ribs) along with several small nodules on the internal surface of adjacent ribs. Some parts of the sixth and seventh ribs, which contained the most number of nodules and also adequate samples of lung tissue and chest wall, adjacent to the erosion site of ribs were resected for histological examination.

\begin{tabular}{|c|c|}
\hline Variable & Data \\
\hline Appearance & Bloody \\
\hline Protein, g/dl & 4.6 \\
\hline LDH, U/L & 205 \\
\hline Glucose, mg/dl & 98 \\
\hline ADA, $U / \mathbf{L}$ & 18 \\
\hline WBC, $(P M N=10 \%, M N=90 \%)$, per $\mathrm{mm}^{3}$ & 1040 \\
\hline $\mathrm{RBC}$, per $\mathrm{mm}^{3}$ & 16500 \\
\hline Cytology & $\begin{array}{l}\text { Negative for } \\
\text { malignancy }\end{array}$ \\
\hline
\end{tabular}
Dehydrogenase.

Figure 1. Chest Computerized Tomography Demonstrates Mild Left Pleural Effusion, Pleural Thickening, Disappearance of Left Anterior Ribs and Suspected Masses
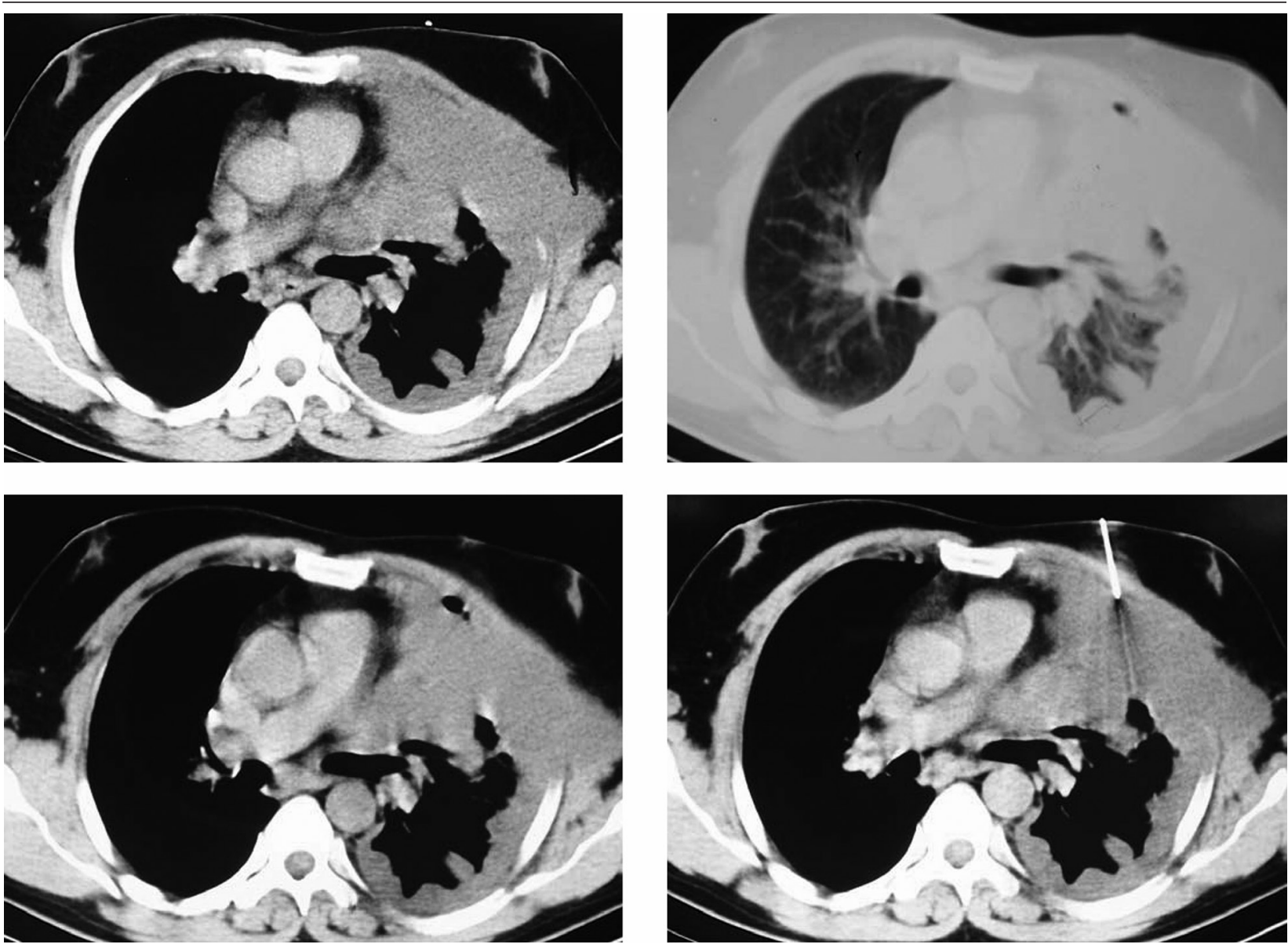

The biopsy needle is seen in the right lower picture. 
Daneshvar Kakhaki A et al.

\begin{tabular}{lc}
\hline \multicolumn{2}{l}{ Table 2. Biochemical Analysis of Pleural Fluid } \\
\hline Variable & Data \\
\hline Appearance & Milky \\
Protein, g/dl & 3.2 \\
LDH, U/L & 269 \\
Glucose, $\mathbf{m g} / \mathbf{d l}$ & 87 \\
Triglycerides, $\mathbf{m g} / \mathbf{d l}$ & 218 \\
\hline
\end{tabular}

a Abbreviations: LDH, Lactate Dehydrogenase.

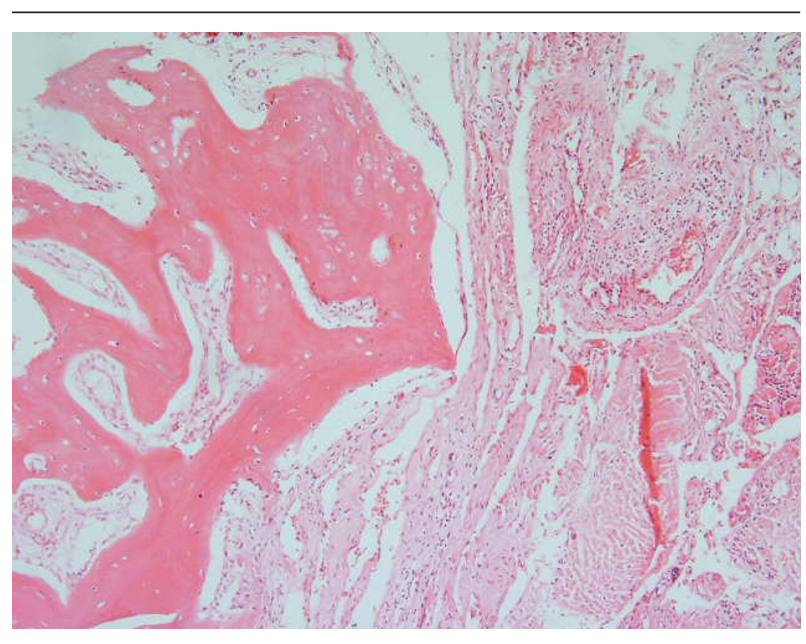

Figure 2. Microscopic section of the biopsy specimen showing extensive diffuse proliferation of thick wall vascular channels including lymphatic vascular channels in all of the received tissue.

Microscopic sections of bone, bone marrow, soft tissue of the chest wall and nerved bundles as well as pleura showed extensive proliferation of variable sized vascular channels, predominantly lymphatic channels, which in some areas were associated with focal chronic lymphocytic infiltration (Figure 2).

Finally along with clinical and radiological findings, microscopic evaluation of the samples established the diagnosis of GD. Thoracic duct ligation was suggested for treatment of chylothorax; considering the general condition of the patient, non-surgical therapies seemed to be more logical. Initially, local radiotherapy of left hemithorax was carried out with an accumulative dose of $40 \mathrm{~Gy}$. Afterwards, pamidronate, $90 \mathrm{mg}$ every 4 weeks was administered. After three injections of pamidronate and several blood transfusions due to anemia, thalidomide, 100 mg per day, was added. After a month, the patient somewhat improved and secretions of the catheter significantly decreased. After four months, the level of hemoglobin gradually increased from 8.5 to $11.5 \mathrm{~g} / \mathrm{dl}$, the patient remarkably gained weight and pleural secretion was completely ceased so the catheter was removed. After seven years of medical therapy, the patient did not complain about any certain problem other than toughness of the lower part of the left hemithorax. In imaging, mild pleural thickening and fibrosis remained stable.

\section{Discussion}

\subsection{History}

In a report of "a boneless arm", Jackson (5) described the first case of massive osteolysis in 1838 and based on later reports by Gorham and Stout this was termed as Gorham's massive osteolysis or Gorham-Stout disease.

\subsection{Etiology and Pathogenesis}

Gorham's disease also known as idiopathic massive osteolysis, disappearing bone disease, phantom bone disease and vanishing bone disease has no genetic basis and it may occur at all ages and in both genders, however, the majority of patients are less than 40 years of age $(1,2,6,7)$. Regarding the etiology of the disease, no evidence of malignancy, neuropathy and/or infection has been detected (2). Despite the first description of the disease more than 50 years ago by Gorham et al. in 1954 and Gorham and Stout in 1955, the exact cause of the disease has not been recognized yet. This rare condition is characterized by uncontrolled, non-malignant proliferation of vascular and lymphatic channels within bones, accompanied by progressive bone destruction and its expansion into the surrounding soft tissues $(2,3)$. In 1955 Gorham and Stout (8) stated that, "the progressive osteolysis is always associated with an angiomatosis of blood and sometimes by lymphatic vessels, which seemingly are responsible for it". Progressive bone resorption may occur spontaneously or following trauma and about $57 \%$ of patients point out trauma in their medical history $(7,9-13)$. The exact bone loss mechanism is not known yet. However, some researchers have noted osteoclastic activity whereas others have not approved such outcome (2, 7, 9-13). Other pathogenetic mechanisms for GD have been suggested including activation of previous silent hamartoma at the site of trauma, neurovascular changes like those seen in Sudeck's atrophy, endothelial dysplasia of lymphatic and blood vessels, primary aberration of vascular tissue due to granulation tissue in bone, mechanical pressure caused by increased vascular tissues and finally activation of local hydrolytic enzymes secondary to local hypoxia and acidosis induced by angiomatosis (12,14-19).

\subsection{Clinical Manifestations}

Although any bone involvement is quite probable, the shoulder and the pelvis are the most common sites of involvement $(2,7,11,20-23)$. The disease has various manifestations depending on the affected bone. Some patients may complain of constant suffering pain, limitation of movement and gradual but progressive weakness, whereas acute onset of pain and swelling in the affected site may be present in others $(1,2,7)$. In some cases pathological fracture of the affected bone leads to diagnosis $(2,4$, 11). In comparison to radiological findings, clinical signs are mild $(24,25)$. Expansion of disease into mediastinum 
through the spine, scapula, ribs and/or sternum involvement may cause pleural or pericardial chylous effusion, which could be life threatening (2-4). Chylothorax is due to the expansion of lymphatic dysplasia to the surface of pleura and/or obstruction or invasion of the thoracic duct (26-28) and has a mortality rate as high as $64 \%$ with medical management and 36\% with surgical treatment $(11,26)$. Osteolysis occurs in a monocentric fashion and spreads to the adjacent bones without respect for articular barriers. In this manner osteolysis of ilium may develop to the proximal portion of the femur or disease in the scapula can extend to the humerus, clavicle and ribs. This kind of spread could be a clue for diagnosis $(1,2,12,24,29$ 31). Development of second osteolytic lesion in another bone after a quiescent period has not been reported (12).

\subsection{Imaging}

Four stages have been described for radiologic appearance of GD $(1-3,24,29,32,33)$. The first or uniphasic stage involves the appearance of intramedullary and subcortical radiolucent foci resembling nondescript patchy osteoporosis. During the second stage concentric shrinkage in tubular bones occurs with tapering of the involved end resulting a "sucked candy" appearance. Cortical erosion along with local invasion of the angiomatous mass into the adjacent soft tissue appears during the third or diphasic stage. The fourth stage is characterized by disappearance of the remaining bone and the possibility of progression of the osteolytic process to multiple contiguous bones. New bone formation does not occur even when osteolysis arrests $(11,12,29,34)$. Radioisotope bone scans, computed tomography (CT) and magnetic resonance imaging (MRI) are other imaging methods that can be used to evaluate the patients; although none of them has the ability to establish a definite diagnosis of GD (2, 13, 34-39). Radioisotope bone scans are useful to demonstrate the monocentric nature of the disease and also to exclude other disorders such as bone tumors, metastases or vascular malignancies. Increased uptake during the initial phase and decreased activity during the delayed phase corresponding to the site of bone loss is shown in bone scans $(2,12,13,28,34-37,39)$. In a threephase scintigraphy of a patient with right radius involvement, Spieth et al. (35) demonstrated slightly decreased activity in the arterial phase, slightly increased activity in the blood pool phase, yet increased activity during the delayed phase with normal thallium activity. They suggested that the reason for decreased activity in the blood flow phase is related to absence of normal remodeling by osteoblasts and osteoclasts and increased activity in the delayed phase is most likely due to the chronic nature of the disease. Computerized tomography is superior to plain radiography to evaluate the extent of the disease and soft tissues involvement $(1,24)$. Computerized tomography is also helpful to guide a biopsy procedure. Three-dimensional CT reconstructions are valuable to plan reconstructive surgery $(24,38,40)$. Mag- netic resonance imaging usually demonstrates low signal intensity on T1-weighted while high signal intensity on T2-weighted images. The difference in the presence of vascular or lymphatic tissues and also in the vascular or fibrosis progression is most probably the reason for variability of signal intensity on T1- and T2-weighted images $(1,2,34-36,38)$. Contrast medium injection will result in enhancement of the lesion $(2,34,38)$. Arteriography, venography and lymphography have been used with low diagnostic yields. Despite the ability to show an increase in blood flow in some cases, angiography has not been useful $(19,24,29,37,40,41)$. Another study suggested that slow blood flow through the wide capillary-like vessels of the lesion is the reason for the ineffectiveness of the angiographic techniques to demonstrate the features of the lesion (41).

\subsection{Laboratory Tests}

All laboratory tests are usually normal except for alkaline phosphatase, which may be slightly elevated in some cases, especially in the presence of associated fracture. In general, laboratory tests are not helpful for diagnosis of GD and they may be valuable only to exclude other diseases $(2,3,11,12,24,32,41)$.

\subsection{Differential Diagnosis}

Variety of local or systemic conditions may be associated with bone or cartilage destruction. These include disuse atrophy, Sudeck's atrophy, primary and metastatic tumors, hyperparathyroidism, gout, congenital pseudarthrosis, granulomatous diseases, rheumatoid arthritis, juvenile idiopathic arthritis, systemic lupus erythematosus, diabetes mellitus, psoriatic arthritis, osteomyelitis, systemic mastocytosis, aseptic necrosis, neurogenic arthropathy, prolonged steroid therapy, bony aneurysm, cystic angiomatosis and also frost bites, animal bites, irradiation, occupational injury, thermal injury and electrocution $(12,42)$. Primary idiopathic osteolysis which is characterized by the spontaneous onset of osteolysis without an obvious reason, is a heterogeneous group of rare conditions that were classified into four types by Torg et al. (43). Macpherson and colleagues (44) added the fifth type to this classification (Table 3$)(12,45)$. According to this classification GD is distinguished from other types of idiopathic osteolysis based on occurrence at any age and in any part of the skeleton and its monocentric pattern and also lack of hereditary pattern or associated nephropathy.

\subsection{Pathology}

Gorham and Stout (8) reviewed the histological sections of eight cases and noted that a marked increase in the number of capillaries first occurs within the affected bones which are found to be dilated and filled with red blood cells. They pointed that these vessels do not disappear after bone resorption but remain either as a vascular 
Daneshvar Kakhaki A et al.

Table 3. Types of Primary Idiopathic Osteolysis According to Hardegger and Colleagues (45)

\begin{tabular}{lr}
\hline Type & Characteristics \\
\hline $\begin{array}{l}\text { Hereditary multicentric } \\
\text { osteolysis with dominant } \\
\text { transmission }\end{array}$ & $\begin{array}{c}\text { Spontaneous beginning of pain and swelling in the hands and feet between the ages of two and } \\
\text { seven years. Involvement of the carpal and tarsal bones in the majority of cases (for this reason } \\
\text { Beals and Bird (46) referred to this disease as carpotarsal osteolysis). It stops normally during } \\
\text { adolescence but can reappear in the third decade of life }\end{array}$ \\
$\begin{array}{l}\text { Hereditary multicentric } \\
\text { osteolysis with recessive } \\
\text { transmission }\end{array}$ & $\begin{array}{r}\text { The clinical appearance is similar to the dominant form. Generalized severe osteoporosis is also } \\
\text { present with cortical thinning and enlargement of the tubular bones. }\end{array}$ \\
$\begin{array}{l}\text { Non-hereditary multicentric } \\
\text { osteolysis with nephropathy }\end{array}$ & $\begin{array}{r}\text { Occurrence in childhood with gradual disappearance of the carpus. Involvement of lesser } \\
\text { degree appears in tarsal bones. Proteinuria can also occur during the onset of osteolysis. Renal } \\
\text { failure and malignant hypertension lead to death in adolescents. }\end{array}$ \\
$\begin{array}{l}\text { Gorham's massive osteolysis } \\
\text { Minchester syndrome }\end{array}$ & $\begin{array}{r}\text { Monocentric pattern and occurrence in any part of the skeleton. It can occur at any age and has } \\
\text { neither a hereditary pattern nor an associated nephropathy. This benign disease is associated } \\
\text { with vascular abnormality, angiomatosis or hemangiomatosis, in the region of osteolysis. The } \\
\text { osteolytic process usually stops after a few years. }\end{array}$ \\
\hline $\begin{array}{r}\text { This autosomal recessive and rare disease starts during childhood with carpotarsal osteolysis. } \\
\text { Contractures, shortness of stature, skin lesions, corneal clouding and osteoporosis are associ- } \\
\text { ated findings. Nephropathy is not seen. Abnormality of fibroblastic function with abnormal } \\
\text { collagen production was found by Hollister and colleagues (47). }\end{array}$ \\
\hline
\end{tabular}

Table 4. Criteria for Diagnosis of Gorham's Disease

\begin{tabular}{l} 
Variables \\
\hline 1) Positive biopsy for angiomatous tissue \\
2) Absence of cellular atypia \\
3) Minimal or no osteoblastic response and absence of \\
dystrophic calcification
\end{tabular}

4) Evidence of local and progressive osseous resorption

5) Non-expansile, nonulcerative lesion

6) Absence of visceral involvement

7) Osteolytic radiographic pattern

8) Negative hereditary, metabolic, neoplastic, immunologic or infectious etiology

9) Spread to adjacent soft tissue

10) Development of fibrous tissue

growth closely resembling that found within the marrow spaces, or as a sponge-like meshwork of freely anastomosing vascular spaces without red blood cells. In general, a histological examination of the affected bone shows a fibrous connective tissue replacing the absorbed bone, which is marked by proliferation of thin-walled vessels and anastomosing dilated endothelium-lined spaces that sometimes contain red blood cells $(1,30,36)$. King (48) suggested "hemangiomatosis" for description of these pathological findings.

\subsection{Diagnosis}

Diagnosis of GD might be delayed from months to years and for accurate and early diagnosis, high clinical suspicion is crucial $(2,42,49)$. Anavi and colleagues (50) noted that the mean duration of symptoms prior to diagnosis was 6.4 years. They also found that the diagnosis of the initial biopsy was incorrect in $45 \%$ of cases. Causes of secondary osteolysis (mentioned above) should be excluded by a thorough history and physical examination, appropriate blood tests and radiographic studies. Also other types of primary idiopathic osteolysis could be ruled out by their characteristics as mentioned in Table 3. The diagnosis of GD could be made on the basis of clinical, radiological and histopathological findings $(2,12,51,52)$. Heffez et al. (4) identified eight diagnostic criteria that help making diagnosis, and are shown in Table 4. Choma added two additional criteria to this list including spread to adjacent soft tissues and development of fibrous tissue $(10,44,53)$.

\subsection{Prognosis}

The natural history of GD is unpredictable. Although spontaneous arrest of osteolysis has been reported in some cases, the disease is inexorably progressive in most patients $(2,3,54)$. Campbell (31) reported pathological fracture and progressive dissolution of the right humerus in a 67-year-old woman who was successfully treated only by simple splintage. Although the humeral shaft gradually reformed and re-ossified over a period of two years without specific treatment, the cause of osteolysis was not clear because the patient refused biopsy. A mortality rate of about $13-16 \%$ has been reported for this rare condition $(1,10,24,51)$. The prognosis is dependent on the site of involvement. High morbidity and mortality rate is seen in case of skull, chest wall or vertebral involvement $(11,42,55,56)$. Tie and colleagues (11) reported a $64 \%$ mortality rate for patients with chylothorax who were treated without surgery. Mediastinal lymphangioma has been rarely associated with GD (24). Yoo et al. (26) reported a case of mediastinal lymphangioma associated with GD in a 38-year-old man. Also in a review of 14 cases of intra- 
thoracic lymphangioma by Brown et al. (57) only one case was associated with GD. Progression to lymphangiosarcoma has not been reported in the literature (58).

\subsection{Treatment}

At present there is no consensus on treating this rare syndrome and different methods of treatment are applied including surgery, radiotherapy and medications alone or in combination $(2,19,36,49,51,59,60)$. As a surgical option resection and reconstruction of the affected bone using bone grafts and/or prostheses has been used, although the success rate is low and bone resorption almost always occurs in the new bone graft $(2,7,17,34,36$, $39,51,56,61)$. Ricalde and colleagues (62) in a report of GD in the maxillofacial region of a five-year-old boy suggested that reconstruction should be undertaken once the disease process is arrested. They delayed reconstruction of the right mandible with two ribs, two years after radiotherapy. Their patient was the second known case of GD in the maxillofacial region during the first decade of life and was the only case that had survived until that time. Turra et al. (63) also reported GD in a 19-year-old male who was successfully treated with an autogenous fibular shaft transplant. They stated that cortical bones show greater resistance to erosion than cancellous bones to the lymphangiomatous osteolytic tissue. They concluded that autogenous bone grafting could be considered as a reasonable alternative to radiotherapy, particularly in young people with monostotic disease localized in bones that are easily operable and have no soft tissue involvement. Radiotherapy, has been widely used for treatment of GD $(1-3,19,27,28,30,34,39,49,51,52,54-56,59-62,64)$ but the possibility of spontaneous arrest obscures any conclusion regarding its efficacy $(36,49,62)$. Radiation doses of 40 to $45 \mathrm{~Gy}$ in 2 Gy fractions has been shown to yield remission rates as high as $60 \%(3,64,65)$. Duffy and colleagues (3) pointed to the several potential advantages of using radiation to treat GD including the possibility of arresting endothelial cell proliferation, its successful use in patient who are poor surgical candidates and also patients who have failed surgical treatments and finally recalcification of affected bone following radiation therapy. Recalcification which is exceedingly rare with other treatment modalities was shown by Choma et al. (10) in 5 of 18 cases of GD treated with radiotherapy. However, the complications of radiotherapy should be considered especially in children including malignant transformation, growth restriction, damage to tooth formation and eruption and finally radiation-induced osteonecrosis of the jaw (49, 51, 60-62). Gastrointestinal tract irritation and resultant nausea and/or vomiting and radiationinduced pneumonia are other complications of radiotherapy (2). Many other therapies have been used for treatment of GD with uncertain effects including vitamin $\mathrm{D}$, parathyroid hormone, estrogen, androgen, calcium, vitamin B12, calcitonin, fluoride, aluminium acetate solu- tion, ultraviolet radiation, magnesium, adrenal extracts, placental extracts, amino acids, calcium, somatotropin and transfusion of placental blood or blood from growing young children $(1,12,19,51,52)$. INF- $\alpha 2 b$, thalidomide and bisphosphonates with their antiangiogenic and antiresorptive effects are also used $(12,30,34,37,58,66)$. It has been reported that zoledronic acid, a nitrogen-containing high potency bisphosphonate, is a more potent inhibitor of osteoclast-mediated bone resorption than all other bisphosphonates, including pamidronate (56, 67,68 ). Mignogna et al. (61) reported a case of GD localized in the mandible of a 24-year-old girl who was treated successfully with zoledronic acid. Hagendoorn et al. (58) used imatinib mesylate for the treatment of GD in a 17-year-old man with chest wall involvement based on expression of platelet-derived growth factor receptor- $\beta$ (PDGF- $\beta$ ) together with the elevated level of circulating PDGF-BB. The drug was discontinued after six days because the patient's respiratory status declined with reaccumulation of pleural fluid and second trial of the drug four weeks later was also aborted when the patient reported increasing respiratory difficulty within three days of starting the medication. Although worsening pleural effusion and deteriorating respiratory function necessitated discontinuation of imatinib mesylate, they concluded that this novel therapy could be of benefit to patient with PDGF-driven lymphangiomas in extrapleural sites. Dupondand colleagues (69) in their report concluded that plasma vascular endothelial growth factor (VEGF) should be considered for diagnosis and follow-up of the course and treatment of disseminated lymphangiomatosis-Gorham-Stout disease. In their patient, who was a 44-year-old woman, the level of plasma VEGF was $163 \mathrm{pg} / \mathrm{ml}$ before interferon therapy and fell to $99 \mathrm{pg} /$ $\mathrm{mL}$, six months after treatment and to $25 \mathrm{pg} / \mathrm{mL}$ after 18 months. After three years of interferon therapy at $15 \mathrm{MIU} /$ week, the dosage was tapered to $10 \mathrm{MIU} /$ week and was followed by an increase of VEGF levels to $131 \mathrm{pg} / \mathrm{mL}$ and after readjustment of Interferon to $15 \mathrm{MIU} /$ week the levels fell again to $43 \mathrm{pg} / \mathrm{mL}$.

As mentioned above, chylothorax is a life threatening complication of GD, which may be associated with a mortality rate as high as $64 \%$ and there is controversy over the optimum treatment for this fatal complication. Surgical options including pleurodesis, pleurectomy, thoracic duct ligation and excision of the pathologic lymphangiomatous tissue have been used for treatment of chylothorax associated with GD $(27,28,59,70)$. Some authors have reported successful treatment of chylothorax with radiation therapy $(3,56)$. As it was shown in the presented case, making the diagnosis of Gorham disease is often delayed and challenging due to its rarity and nonspecific manifestations which initially lead to more prevalent diagnoses. Another factor, which also affects delayed diagnosis, is delayed radiological findings. It seems that a combination of radiotherapy, pamidronate and thalidomide in the presented case could keep the disease in re- 
mission at least for seven years. However, according to the slow and gradual trend of improvement in this case, it might not be possible to consider exact improvement because of the delayed effect of radiotherapy, Pamidronate-Thalidomide therapy or even course of the disease itself. Therefore further studies and experiences are needed in this regard. We suggest that this disease has to be considered among differential diagnoses for patients with chest pain, pleural effusion and/or chylothorax with unknown reason and particularly with history of chest trauma. In suspected cases, it is essential to examine biopsy specimens of the bone adjacent to the inflammated tissues in order to confirm diagnosis. Gorham (8) in his historical report more than fifty years ago pointed to the Mouchet's personal opinion who stated that; "the day will come when some new, well observed facts, submitted to careful clinical examination and to complete laboratory investigation, will permit us to elucidate the cause of this singular osteolysis and to cure it" and it seems that this day has not come yet.

\section{Authors' Contributions}

Drafting of the manuscript and review of the literature: Abolghasem Daneshvar Kakhaki. Review of the literature and revision of the manuscript: Saviz Pejhan, Kian Khodadad, Mehrdad Arab, Reza Saghebi, Mohammad Behgam Shadmehr. Gathering of information and revision of the manuscript: Roya Farzanegan. Writing about pathology in the manuscript and review of the literature: Shirin Karimi.

\section{References}

1. Okafuji T, Yabuuchi H, Soeda H, Takahashi N, Hatakenaka M, Sakai S, et al. Gorham's disease of the chest wall: CT and MR characteristics. J Thorac Imaging. 2005;20(4):284-7.

2. Patel DV. Gorham's Disease or Massive Osteolysis. Clin Med Res. 2005;3(2):65-74.

3. Duffy BM, Manon R, Patel RR, Welsh JS. A Case of Gorham's Disease with Chylothorax Treated Curatively with Radiation Therapy. Clin Med Res. 2005;3(2):83-6.

4. Heffez L, Doku HC, Carter BL, Feeney JE. Perspectives on massive osteolysis. Oral Surg Oral Med Oral Pathol Oral Radiol Endod. 1983;55(4):331-43.

5. Jackson JBS. A boneless arm. Boston Med SurJ.1838;18:368-9.

6. Jayaprakash B, Prajeesh B, Niar DS. Gorham's disease.J Assoc Physicians India. 2013;61:71-3.

7. Rubel IF, Carrer A, Gilles JJ, Howard R, Cohen G. Progressive Gorham disease of the forearm. Orthopedics. 2008;31(3):284.

8. Gorham LW, Stout AP. Massive osteolysis (acute spontaneous absorption of bone, phantom bone, disappearing bone); its relation to hemangiomatosis. J Bone Joint Surg Am. 1955;37-A(5):9851004.

9. Tripathy SK, Sen RK, Goyal T, Gupta N. Gorham disease of the proximal femur: a case report and review of published reports. Orthop Surg. 2013;5(1):72-6.

10. Choma ND, Biscotti CV, Bauer TW, Mehta AC, Licata AA. Gorham's syndrome: A case report and review of the literature. Am J Med. 1987;83(6):1151-6.

11. Tie ML. Chylothorax in Gorham's syndrome. A common complication of a rare disease. CHEST Journal.1994;105(1):208.

12. Moller G, Priemel M, Amling M, Werner M, Kuhlmey AS, Delling
G. The Gorham-Stout syndrome (Gorham's massive osteolysis). J Bone Joint Surg Br.1999;81(3):501-6.

13. Chen CY, Shih WJ, Fan YM, Huang WS, Lee HS. Gorham's Disease of the Skull Demonstrated by Bone SPECT-CT. Ann Nucl Med Sci. 2004;17:233-6.

14. Knoch HG. Die gorhamsche krankheit aus klinischer sicht. Zentralbl Chir.1963;18:674-83.

15. Lichtenstein L. Diseases of bone and joints.St Louis: Mosby; 1975.

16. Young JWR, Galbraith M, Cunningham J, Roof BS, Vujic I, Gobien $\mathrm{RP}$, et al. Case report: Progressive vertebral collapse in diffuse angiomatosis. Metab Bone Dis Relat Res. 1983;5(2):53-60.

17. Heyden G, Kindblom LG, Nielsen JM. Disappearing bone disease. A clinical and histological study. J Bone Joint Surg Am. 1977;59(1):57-61.

18. Thompson JS, Schurman DJ. Massive osteolysis. Case report and review of literature. Clin Orthop Relat Res. 1974(103):206-11.

19. Aizawa T, Sato T, Kokubun S. Gorham disease of the spine: a case report and treatment strategies for this enigmatic bone disease. Tohoku J Exp Med. 2005;205(2):187-96.

20. Hofbauer LC. GorhamStout disease (phantom bone) of the shoulder girdle. Rheumatology.1999;38(9):904-5.

21. Bode-Lesniewska B, von Hochstetter A, Exner GU, Hodler J. Gorham-Stout disease of the shoulder girdle and cervico-thoracic spine: fatal course in a 65-year-old woman. Skeletal Radiol. 2002;31(12):724-9.

22. Boyer P, Bourgeois P, Boyer O, Catonne Y, Saillant G. Massive Gorham-Stout syndrome of the pelvis. Clin Rheumatol. 2005;24(5):551-5.

23. Chavanis N, Chaffanjon P, Frey G, Vottero G, Brichon PY. Chylothorax complicating Gorham's disease. Ann Thorac Surg. 2001;72(3):937-9.

24. Collins J. Case 92: Gorham syndrome. Radiology. 2006; 238(3):1066-9.

25. Ross JL, Schinella R, Shenkman L. Massive osteolysis. Am J Med. 1978;65(2):367-72.

26. Yoo SY, Goo JM, Im JG. Mediastinal Lymphangioma and Chylothorax: Thoracic Involvement of Gorham's Disease. Korean J Radiol. 2002;3(2):130.

27. Underwood J, Buckley J, Manning B. Gorham disease: an intraoperative case study. AANA J. 2006;74(1):45-8.

28. Lee WS, Kim SH, Kim IH, Kim HK, Lee KS, Lee SY, et al. Chylothorax in Gorham's Disease. Journal of Korean Medical Science. 2002;17(6):826.

29. Torg JS, Steel HH. Sequential roentgenographic changes occurring in massive osteolysis. J Bone Joint Surg Am. 1969;51(8):1649-55.

30. Hammer F, Kenn W, Wesselmann U, Hofbauer LC, Delling G, Allolio B, et al. Gorham-Stout disease--stabilization during bisphosphonate treatment. J Bone Miner Res. 2005;20(2):350-3.

31. Campbell J, Almond HG, Johnson R. Massive osteolysis of the humerus with spontaneous recovery. J Bone Joint Surg Br. 1975;57(2):238-40.

32. Patrick JH. Massive osteolysis complicated by chylothorax successfully treated by pleurodesis. J Bone Joint Surg Br. 1976;58(3):347-9.

33. Johnson PM, Mc CJ. Observations on massive osteolysis; a review of the literature and report of a case. Radiology. 1958;71(1):28-42.

34. van der Linden-van der Zwaag H, Onvlee GJ. Massive osteolysis (Gorham's disease) affecting the femur. Acta Orthop Belg. 2006;72(3):261-8.

35. Spieth ME, Greenspan A, Forrester DM, Ansari AN, Kimura RL, Gleason-Jordan I. Gorham's disease of the radius: radiographic, scintigraphic, and MRI findings with pathologic correlation. A case report and review of the literature. Skeletal Radiol. 1997;26(11):659-63.

36. Dominguez R, Washowich TL. Gorham's disease or vanishing bone disease: plain film, CT, and MRI findings of two cases. Pediatr Radiol. 1994;24(5):316-8.

37. Wong JW, Yip DK, Kong JK, Chien EP, Shek TW. Use of bisphosphonate to manage avulsion fracture of tibial tuberosity with underlying angiomatosis: a case report. J Orthop Surg (Hong Kong). 2003;11(1):97-100. 
38. Chung C, Yu JS, Resnick D, Vaughan LM, Haghighi P. Gorham syndrome of the thorax and cervical spine: CT and MRI findings. Skeletal Radiol.1997;26(1):55-9.

39. Piggott B. Now you see it, now you don't-a case of "Vanishing Bone". J Med Radiat Sci. 2004;51(2):67-70.

40. Vinee P, Tanyu MO, Hauenstein KH, Sigmund G, Stover B, Adler CP. CT and MRI of Gorham syndrome. J Comput Assist Tomogr. 1994;18(6):985-9.

41. Sharma A, Iyer N, Mittal A, Das D, Sharma S. Vanishing mandible. J Oral Sci. 2010;52(3):513-6.

42. Verma A, Mohan S, Kathuria MK, Phadke S, Baijal SS. Primary idiopathic osteolysis syndrome: Case report and review of literature. J Clin Diagn Res. 2007;1:79-81.

43. Torg JS, DiGeorge AM, Kirkpatrick JA, Jr., Trujillo MM. Hereditary multicentric osteolysis with recessive transmission: a new syndrome. J Pediatr. 1969;75(2):243-52.

44. Macpherson RI, Walker RD, Kowall MH. Essential osteolysis with nephropathy. J Can Assoc Radiol. 1973;24(2):98-103.

45. Hardegger F, Simpson LA, Segmueller G. The syndrome of idiopathic osteolysis. Classification, review, and case report. J Bone Joint Surg Br. 1985;67(1):88-93.

46. Beals RK, Bird CB. Carpal and tarsal osteolysis. A case report and review of the literature. J Bone Joint Surg Am. 1975;57(5):681-6.

47. Hollister DW, Rimoin DL, Lachman RS, Cohen AH, Reed WB, Westin GW. The Winchester syndrome: a nonlysosomal connective tissue disease. J Pediatr.1974;84(5):701-9.

48. King DJ. A case resembling hemangiomatosis of the lower extremity. J Bone Joint Surg Am. 1946;28:623-8.

49. Malde R, Agrawal HM, Ghosh SL, Dinshaw KA. Vanishing bone disease involving the pelvis. J Cancer Res Ther. 2005;1(4):227-8.

50. Anavi Y, Sabes WR, Mintz S. Gorham's disease affecting the maxillofacial skeleton. Head Neck. 1989;11(6):550-7.

51. Kai B, Ryan A, Munk PL, Dunlop P. Gorham disease of bone: three cases and review of radiological features. Clin Radiol. 2006;61(12):1058-64.

52. Gillham CM, Hollywood D, Dunne B. Gorham's syndrome. Clin Oncol (R Coll Radiol). 2005;17(1):57-8.

53. Auge B, Toussirot E, Kantelip B, Wendling D. From polycystic bone angiomatosis to Gorham's disease. Two case-reports and literature review. Rev Rhum Engl Ed.1998;65(3):201-6.

54. McNeil KD, Fong KM, Walker QJ, Jessup P, Zimmerman PV. Gorham's syndrome: a usually fatal cause of pleural effusion treated successfully with radiotherapy. Thorax.1996;51(12):1275-6.

55. Escande C, Schouman T, Francoise G, Haroche J, Menard P, Piette IC, et al. Histological features and management of a mandibular
Gorham disease: a case report and review of maxillofacial cases in the literature. Oral Surg Oral Med Oral Pathol Oral Radiol Endod. 2008;106(3):e30-7.

56. Patel RM, Ward D, Moran N. Gorham's disease: a case report and literature review. Oral Surg. 2008;1:201-5.

57. Brown LR, Reiman HM, Rosenow EC, Gloviczki PM, Divertie MB. Intrathoracic Lymphangioma. Mayo Clin Proc. 1986;61(11):882-92.

58. Hagendoorn J, Padera TP, Yock TI, Nielsen GP, di Tomaso E, Duda DG, et al. Platelet-derived growth factor receptor-beta in Gorham's disease. Nat Clin Pract Oncol. 2006;3(12):693-7.

59. Boyle MJ, Alison P, Taylor G, Lightbourne BA. A case of Gorham's disease complicated by bilateral chylothorax. Heart Lung Circ. 2008;17(1):64-6.

60. Kiran DN, Anupama A. Vanishing bone disease: a review. J Ora Maxillofac Surg. 2011;69(1):199-203.

61. Mignogna MD, Fedele S, Lo Russo L, Ciccarelli R. Treatment of Gorham's disease with zoledronic acid. Oral Oncol.2005;41(7):747-50.

62. Ricalde P, Ord RA, Sun CC. Vanishing bone disease in a five yea old: report of a case and review of the literature. Int J Oral Maxillofac Surg. 2003;32(2):222-6.

63. Turra S, Gigante C, Scapinelli R. A 20-year follow-up study of a case of surgically treated massive osteolysis. Clin Orthop Relat Res. 1990(250):297-302.

64. Dunbar SF, Rosenberg A, Mankin H, Rosenthal D, Suit HD. Gorham's massive osteolysis: the role of radiation therapy and a review of the literature. Int J Radiat Oncol Biol Phys. 1993;26(3):491-7.

65. Swelstad MR, Frumiento C, Garry-McCoy A, Agni R, Weigel TL. Chylotamponade: an unusual presentation of Gorham's syndrome. Ann Thorac Surg. 2003;75(5):1650-2.

66. Ezekowitz RA, Mulliken JB, Folkman J. Interferon alfa-2a therapy for life-threatening hemangiomas of infancy. $N$ Engl J Med. 1992;326(22):1456-63.

67. Croucher P, Jagdev S, Coleman R. The anti-tumor potential of zoledronic acid. Breast. 2003;12:S30-6.

68. Green JR, Rogers MJ. Pharmacologic profile of zoledronic acid: A highly potent inhibitor of bone resorption. Drug Devel Res. 2002;55(4):210-24.

69. Dupond JL, Bermont L, Runge M, de Billy M. Plasma VEGF determination in disseminated lymphangiomatosis-Gorham-Stout syndrome: a marker of activity? A case report with a 5-year follow-up. Bone. 2010;46(3):873-6.

70. Hejgaard N, Olsen PR. Massive Gorham osteolysis of the right hemipelvis complicated by chylothorax: report of a case in a 9-year-old boy successfully treated by pleurodesis. J Pediatr Orthop. 1987;7(1):96-9. 